\title{
APRENDER CIÊNCIAS NA EDUCAÇÃO PRÉ-ESCOLAR: O CASO DA FLUTUAÇÃO E AFUNDAMENTO DE OBJETOS EM ÁGUA
}

\section{LEARNING SCIENCES IN PRESCHOOL EDUCATION: THE CASE OF FLOATING AND SINKING OF OBJECTS IN WATER}

\author{
Paulo Varela ${ }^{1}$ \\ Maria João $\operatorname{Mota}^{2}$ \\ Cléria Maria Wendling ${ }^{3}$
}

\begin{abstract}
Resumo: Este artigo analisa o processo de exploração de uma atividade sobre a flutuação de objetos em água, promovido com crianças da educação pré-escolar. A atividade integrou-se numa intervenção pedagógica que teve como objetivo promover uma abordagem prática e investigativa das ciências. A análise incide no diário de campo do educador-investigador. Os resultados revelam que as explicações iniciais das crianças sobre a flutuação incluem uma única característica física dos objetos. O peso tende a dominar, através do esquema "pesado afunda" e "leve flutua". A combinação dos dados do diário com os resultados da avaliação das aprendizagens mostra que as crianças reconhecem a existência de objetos pesados que flutuam e leves que afundam e algumas são capazes de relacionar o peso do objeto com a força da água impulsão, em situação de flutuação. São ainda identificadas estratégias promotoras dessas aprendizagens, destacando-se o papel de suporte e orientação do educador.
\end{abstract}

Palavras-chave: Aprendizagem por Investigação; Flutuação e Afundamento; Educação Pré-escolar.

Abstract: This article analyses the process of exploring an activity on the floating of objects on water, promoted with children. The activity was part of a pedagogical intervention that aimed to promote a practical and investigative approach to science learning. The analysis focuses on the educator-researcher field diary. The results show that the children's initial explanations of floating include only one physical characteristic of the objects. The weight tends to dominate, through the "heavy sinks" and "light floats" scheme. The combination of data from the diary with the results of the learning assessment shows that children recognize the existence of heavy objects that float and light ones that sink and some are able to relate the object's weight with the water's upthrust force in a floating situation. Strategies that promote these learnings are also identified, with highlight to the educator's support and guidance role.

Keywords: Inquiry-based Science Learning; Floating and Sinking; Preschool Education.

\footnotetext{
${ }^{1}$ Doutor em Estudos da Criança, na especialidade de Estudo do Meio Físico, pela Universidade do Minho (UMinho). Professor Auxiliar do Instituto de Educação da Universidade do Minho e Investigador do Centro de Investigação em Estudos da Criança (CIEC), Braga, Portugal. E-mail: pibvarela@ie.uminho.pt

${ }^{2}$ Mestre em Educação Pré-Escolar e Ensino do $1 .^{\circ}$ Ciclo do Ensino Básico pela Universidade do Minho (UMinho). Professora no Centro Escolar de Vila Verde, Braga, Portugal. E-mail: mjl_motta@ hotmail.com

${ }^{3}$ Doutoranda no Programa de Pós-Graduação em Educação em Ciências e Educação Matemática, Universidade Estadual do Oeste do Paraná (UNIOESTE). Professora Assistente do Curso de Pedagogia UNIOESTE, Cascavel, Paraná, Brasil. E-mail: cleriamwe@ gmail.com
} 


\section{Introdução}

As ciências físico-naturais constituem uma importante área de conteúdo no desenvolvimento e aprendizagem das crianças na primeira infância. Em Portugal, fazem parte da área do "Conhecimento do Mundo" das "Orientações Curriculares para a Educação Pré-escolar”. Esta área marca o início das aprendizagens das diferentes ciências naturais e sociais, de modo a fomentarem e a estruturarem na criança um pensamento científico cada vez mais elaborado, que lhe permita compreender e interpretar o mundo que a rodeia. A sua abordagem deve ser dotada de rigor científico, contextualizada e integradora de diversos saberes,

onde se procura que a criança adote uma atitude de questionamento e de procura organizada do saber, própria da metodologia científica, de modo a promover uma melhor compreensão do mundo físico, social e tecnológico que a rodeia (SILVA et al., 2016, p. 7).

O conhecimento do mundo físico e natural pretende proporcionar experiências de aprendizagem que permitam desenvolver nas crianças, em idade pré-escolar, um conjunto de saberes relativos "à biologia, (conhecimento dos órgãos do corpo, dos animais, do seu habitat e costumes, de plantas, etc.) e ainda à física e à química (luz, ar, água, etc.)" (SILVA et al., 2016, p. 93). As orientações curriculares sugerem ao educador uma abordagem às ciências de natureza prática e socioconstrutivista, enfatizando a realização de determinadas atividades, como, por exemplo: "mistura de água com areia, com açúcar, com azeite; objetos que flutuam e não flutuam; efeitos de luz e sombra, atração por um íman; gelo que derrete, mistura de cores, etc.". Há ainda insistência em fomentar nas crianças uma "atitude de pesquisa, centrada na capacidade de observar, no desejo de experimentar, na curiosidade de descobrir numa perspetiva crítica e de partilha do saber" ou simplesmente uma "atitude científica e experimental" (SILVA et al., 2016, p. 89). A promoção dessa atitude pressupõe o desenvolvimento de um processo de "descoberta fundamentada", que "parta dos interesses das crianças e dos seus saberes" e recorra a situações ou problemas, em que elas tenham a "oportunidade de propor explicações, de desenvolver conjeturas e de confrontar entre si as suas "teorias" e perspetivas sobre a realidade" (SILVA et al., 2016, p. 89). Nestas circunstâncias, a educação pré-escolar constitui um espaço formal onde as crianças podem e devem começar a desenvolver, no domínio das ciências, um importante conjunto de conhecimentos, processos e atitudes que lhes permitam continuar a aprender. 
DOI:https://doi.org/10.33238/ReBECEM.2020.v.4.n.3.24906

É amplamente reconhecido que as crianças, desde tenra idade, manifestam capacidade e curiosidade natural para observar, explorar e descobrir o mundo à sua volta. As primeiras experiências formais de ciências podem e devem potenciar estas qualidades naturais das crianças (FRENCH, 2004), pois elas constituem o suporte prévio necessário para que sejam envolvidas num processo de aprendizagem ativa, reflexiva e significativa do conhecimento. Trata-se, de acordo com Furman (2009), de “educar" essa curiosidade natural das crianças para hábitos do pensamento mais sistemáticos, profundos e autónomos; estimulando-as a colocar perguntas, a pesquisar e a elaborar possíveis explicações para o que fazem e observam; a construir formas de testar as suas ideias, a partilhar e a discuti-las com os outros (HARLEN; QUALTER, 2018).

Trata-se, em suma, de utilizar esse desejo natural de conhecer o mundo [...] como plataforma sobre a qual possam construir ferramentas de pensamento que lhes permitam compreender como as coisas funcionam, e pensar por eles mesmos. E, também, de que o prazer que se obtém ao compreender melhor o mundo alimente a chama de sua curiosidade e a mantenha viva (FURMAN, 2009, p. 7).

Deste modo, as atividades de ciências que estimulam a exploração e a investigação são cruciais para o desenvolvimento e a manutenção dessa curiosidade, bem como para o desenvolvimento de competências de processos científicos simples (FRENCH; WOODING, 2013), como, por exemplo, observar, fazer perguntas, prever, experimentar, interpretar e discutir os resultados das suas descobertas (GERDE et al., 2013). As ciências, enquanto processo, promovem excelentes oportunidades para uma aprendizagem centrada na ação das crianças e na reflexão sobre a sua própria ação (VARELA, 2014). Neste contexto de aprendizagem, usam e desenvolvem não só competências físicas, mas fundamentalmente cognitivas (JONES et al., 2008), em particular competências investigativas (FRENCH; WOODING, 2013).

Uma abordagem prática e investigativa das ciências na educação pré-escolar proporciona, também, amplas oportunidades para o uso e desenvolvimento integrado de saberes de outros domínios, especificamente da linguagem e da matemática (GERDE et al., 2013; PATRICK et al., 2013), bem como é suscetível de promover a motivação das crianças para a ciência em fases posteriores da sua vida (PATRICK; MANTZICOPOULOS, 2015).

A qualidade das experiências de aprendizagem em ciências é essencial para ajudar as crianças: a compreender o mundo à sua volta; a obter e organizar informações; a 
DOI:https://doi.org/10.33238/ReBECEM.2020.v.4.n.3.24906

desenvolver formas de descobrir, testar ideias e utilizar as evidências; a desenvolver ideias que, em vez de obstaculizarem, ajudem a aprendizagem posterior de ciências; e a gerar atitudes mais positivas e conscientes face à ciência (HARLEN, 2008).

Eshach e Fried (2005) referem seis razões que sustentam a ideia de que as crianças, em idade pré-escolar, devem ser expostas à ciência: a) elas gostam naturalmente de observar e pensar sobre a natureza; b) permite desenvolver atitudes positivas em relação à ciência; c) uma exposição precoce aos fenómenos científicos favorece uma melhor compreensão dos conceitos científicos estudados mais tarde; d) o uso de uma linguagem cientificamente informada, em idade precoce, influencia o eventual desenvolvimento de conceitos científicos; e) as crianças podem compreender os conceitos científicos e pensar cientificamente; f) a ciência é um meio eficiente para desenvolver o pensamento científico.

As características do mundo moderno requerem também uma educação científica precoce, para que os futuros cidadãos estejam apetrechados para viver nele (SÁ, 2002), assumindo-se como sujeitos participativos, críticos e informados na tomada das suas decisões. Segundo Fiolhais "uma criança que não fique próxima da ciência na idade dos "porquês" [...] dificilmente estará preparada para a vida, que, atualmente, se vê cada vez mais dependente da ciência e da tecnologia" (2012, p. 59).

Assim, nos primeiros níveis educativos, a educação científica é essencial para desenvolver nas crianças as bases do pensamento científico, uma compreensão básica dos fenómenos naturais e as atitudes positivas em relação à ciência e à sua aprendizagem, as quais terão uma importância fundamental no seu desenvolvimento e nas suas aprendizagens ulteriores (HARLEN, 2008; SÁ, 2003). Infelizmente, o enorme potencial de desenvolvimento e aprendizagem das crianças, aliado à sua natural curiosidade e interesse pelos fenómenos físicos e naturais, continuam a não ser devidamente explorados. Em alguns contextos de educação pré-escolar, as crianças têm poucas oportunidades de realizar atividades práticas de ciências, que promovam o desenvolvimento de competências e saberes essenciais a uma melhor compreensão e integração no mundo que as rodeia. Segundo Martins et al. (2009), no pré-escolar a educação em ciências tem sido deixada para segundo plano,

sendo amiúde pouco enriquecedoras as experiências de aprendizagem proporcionadas às crianças, e observando-se um fosso entre aquilo que elas são capazes de fazer e compreender e as experiências a que têm acesso no jardim de infância (p. 15). 
No quadro das preocupações e orientações curriculares anteriores, desenvolveu-se um projeto de intervenção pedagógica de ciências, que teve como objetivo geral promover, num contexto de educação pré-escolar, uma abordagem prática e investigativa das ciências, baseada no papel ativo e construtivo da criança, em interação social com os seus pares e com a educadora. O presente artigo é parte integrante dessa intervenção e pretende, de forma particular, com base na exploração de uma atividade sobre a flutuação de objetos em água dar resposta às seguintes questões de investigação: a) Que explicações iniciais apresentam as crianças sobre a flutuação dos objetos em água?; b) Serão as crianças capazes de desenvolver uma melhor compreensão da flutuação, em termos da relação de grandeza entre o peso do objeto e a força da água (impulsão)?; c) Se sim, que processos promovem essa melhor compreensão sobre o diferente comportamento dos objetos em água?

\section{Explicações e perspetivas de aprendizagem das crianças sobre a flutuação}

A flutuação dos objetos é um dos fenómenos que mais intriga as crianças, principalmente as mais jovens, e está, desde cedo, ligado às suas experiências quotidianas, quando, por exemplo, durante o banho, brincam e observam o comportamento dos objetos na água. Em crianças de idade pré-escolar, vários estudos identificaram diferentes tipos de explicações não científicas para a flutuação. Um tipo de explicação assume um caráter puramente moral, sem mencionar nenhuma característica física dos objetos. Por exemplo, Piaget verificou que, num primeiro estádio, que vai dos 4 aos 5 anos de idade, as crianças atribuíram a flutuação de um barco a uma necessidade moral de obediência ligada à vontade dos seus criadores - "é a coisa certa a fazer" (2001, p. 136).

Um segundo tipo de explicação aponta para causas dinâmicas relacionadas com o movimento do objeto. Num segundo estádio em Piaget (2001), crianças de 5 e 6 anos de idade explicaram a flutuabilidade de um barco com base na capacidade deste se movimentar - "porque eles se movem", "porque eles têm velas", "porque têm motor".

Um terceiro tipo de explicação envolve uma única propriedade ou característica física de um objeto. Num estudo realizado por Butts et al. (1993), as crianças começaram por explicar o diferente comportamento dos objetos na água com base no seu tamanho, peso, material, cor ou dureza. Kallery (2015) verificou que o tamanho, o peso e a forma são características físicas que as crianças de 4 a 6 anos de idade relacionam inicialmente com a flutuação de um objeto. Também no estudo de Hsin e Wu (2011), crianças de 4 e 5 
DOI:https://doi.org/10.33238/ReBECEM.2020.v.4.n.3.24906

anos de idade, antes da intervenção, apresentaram explicações, que incluíam, por exemplo, um dos seguintes fatores: peso, volume, material, cor, resistência, poder da água, ar, etc. Porém, quase metade das explicações das de 4 anos estava relacionada com o peso e o volume dos objetos, enquanto a maioria das de 5 anos usava o peso como único fator para explicarem a flutuação. A maioria das crianças de ambas as idades, que referiu o peso, considerou que um objeto afunda porque é pesado e flutua porque é leve. O dinamismo que caracteriza o segundo estádio de Piaget (2001) também se manifesta no peso dos objetos, mas como sinal de "força". As crianças consideraram que os barcos são capazes de flutuar porque são pesados, ou seja, têm força para se manterem em pé e resistirem ao poder da água. As características dos objetos, que influenciam as explicações das crianças, são geralmente percetivas e o tipo de explicação inicial parece depender muito das experiências manipulativas das crianças (HSIN; WU, 2011).

Porém, nenhuma das explicações anteriores é cientificamente correta. Para se ajuizar a flutuabilidade de um corpo é necessário comparar a intensidade da força de impulsão, a que o corpo fica sujeito, quando parcial ou totalmente imerso num fluído (líquido ou gás), com a intensidade do peso do próprio corpo. Peso do corpo e impulsão são duas forças que atuam na vertical e em sentidos contrários: peso para baixo e impulsão para cima. O comportamento do corpo no fluído é o resultado do balanço entre estas duas forças. No entanto, é também frequente a explicação da flutuação recorrendo à densidade do corpo e à densidade do fluído, como se de duas explicações diferentes se tratasse. Ora, a relação de grandeza entre aquelas densidades é uma dedução matemática da relação de grandeza entre o peso do corpo e a impulsão (SÁ, 2009).

O conceito de densidade é muito difícil para as crianças o entenderem, pois exige a coordenação de duas propriedades de um objeto, a massa e o volume. Embora reconheçam que se trata de conceitos demasiado difíceis e abstratos para crianças em idade pré-escolar, estudos anteriores têm realizado intervenções que orientam as crianças a se concentrarem no "tipo de material" de que um objeto é feito, em vez de utilizarem o conceito de densidade (por exemplo, HAVU-NUUTINEN, 2005; KALLERY, 2015; HSIN; WU, 2011).

Piaget (2001) referiu que as crianças não entendem completamente o conceito de densidade até ao final da infância (cerca de 9 anos). Sá (2002) verificou que somente algumas crianças de 9/10 anos de idade conseguiram fazer uma certa coordenação entre peso e volume, para explicarem a flutuação. Tal coordenação assumiu diferentes formulações como: corpo com peso grande e tamanho pequeno afunda-se; corpo com peso 
DOI:https://doi.org/10.33238/ReBECEM.2020.v.4.n.3.24906

pequeno e volume grande flutua; quando o peso está todo no mesmo sítio o corpo afundase. Em qualquer dos casos, estamos perante uma noção intuitiva de densidade, para explicar o comportamento dos objetos na água.

No entanto, alguns estudos têm demonstrado que crianças em idade pré-escolar são capazes de desenvolver explicações mais corretas sobre a flutuação (BUTTS et al, 1993; KOHN, 1993; HAVU-NUUTINEN, 2005; HSIN; WU, 2011; KALLERY, 2015; TEO et al., 2017). Por exemplo, Kohn (1993) descobriu que, embora não consigam integrar duas propriedades de um objeto, as crianças de 4 e 5 anos já possuíam algum conhecimento sobre densidade e sua relação com a flutuação. Quando solicitadas a prever se determinados objetos flutuavam ou afundavam na água, as crianças foram mais propensas a efetuarem julgamentos corretos quando a densidade de um objeto era muito maior ou muito menor do que a da água. Os resultados pós-intervenção obtidos por Kallery (2015), com objetos sólidos e ocos, revelaram altas percentagens de crianças de 4 a 6 anos de idade que redirecionaram a sua atenção para o tipo de material de que o objeto é feito, como fator determinante para o seu comportamento na água.

Estudos anteriores evidenciaram também que a experiência manipulativa com os objetos, por si só, não é suficiente para que crianças pequenas desenvolvam um melhor entendimento sobre a flutuação. Por exemplo, Butts et al. (1993) mostraram que crianças de 5 e 6 anos desenvolveram um melhor entendimento sobre flutuar e afundar quando tiveram a oportunidade de manipular, conversar e discutir as suas explicações, sob a orientação do adulto. Também Hsin e Wu (2011) verificaram que a combinação de estratégias de scaffolding, através das quais o adulto incentiva, orienta e ajuda as crianças, com a perceção das crianças sobre os materiais de que são feitos os objetos é mais eficaz para melhorar a compreensão das crianças pequenas sobre a flutuação. No grupo de 5 anos, três em cada cinco crianças conseguiram relacionar o material de um objeto à sua flutuabilidade e generalizaram as suas explicações aos objetos feitos do mesmo material.

\section{Procedimentos metodológicos}

O projeto de intervenção pedagógica de ciências foi desenvolvido com um grupo de vinte e três crianças de uma sala de um jardim de infância público, situado nas proximidades da cidade de Braga - Portugal. O grupo era constituído por doze crianças de 5 anos (três meninas e nove meninos) e onze de 4 anos (sete meninas e quatro meninos). 
DOI:https://doi.org/10.33238/ReBECEM.2020.v.4.n.3.24906

O projeto desenvolveu-se segundo uma metodologia qualitativa do tipo interpretativo (GUBA; LINCOLN, 2000), que assumiu o caráter de investigação-ação (LATORRE, 2004; MACNAUGHTON; HUGHES, 2011). Cada ciclo interativo de planificação, ação, observação e avaliação correspondeu ao processo educativo inerente à exploração de uma atividade de ciências com as crianças.

As atividades foram exploradas pelo segundo autor, que, já bastante familiarizado com as crianças e com a educadora titular do grupo, desempenhou, simultaneamente, o papel de educador e investigador. Foram planificadas e exploradas 7 atividades de ciências, de acordo com os interesses manifestados previamente pelas crianças. O tempo de intervenção perfez um total de 15 horas, durante dois meses e com uma cadência de exploração de uma atividade por semana. As atividades abordaram diversos temas, como a flutuação de objetos em água, a dissolução de materiais sólidos em água, as propriedades magnéticas dos materiais, a forma da Terra, o dia e a noite, a germinação de sementes, as plantas e os animais do ambiente próximo.

No caso da atividade sobre a flutuação de objetos em água, pretendeu-se promover uma iniciação ao estudo deste fenómeno, de modo a averiguar-se se as crianças são capazes de compreender que a flutuação de um corpo depende da relação de grandeza entre duas forças de sentidos contrários, o seu peso e a força da água - a impulsão.

Na exploração das atividades adotou-se uma abordagem prática e investigativa das ciências, em que foram privilegiadas, entre outras, as seguintes estratégias pedagógicas: a) proporcionar às crianças oportunidades para manusearem e explorarem os objetos; b) colocar perguntas que estimulam o pensamento e a ação das crianças; c) promover a discussão de ideias, estratégias e observações no seio do grupo; d) fornecer o suporte e a ajuda necessária, para que as crianças possam operar num nível cognitivo mais elevado scaffolding; e) confrontar as crianças com evidências e situações discrepantes que contrariam as suas ideias; f) incentivar as crianças a avaliarem a consistência das suas ideias e explicações à luz das evidências disponíveis e a considerarem explicações alternativas; g) utilizar formas de registo das observações, de forma a apoiarem e a reverem as aprendizagens efetuadas; $h$ ) ajudar as crianças a usarem processos científicos simples e a desenvolverem, simultaneamente, competências de investigação (HARLEN, 2014; PRISCINET, 2014).

No contexto destas estratégias, o educador-investigador envolveu-se e participou ativamente com as crianças, interagindo com elas para melhor compreender os diferentes 
DOI:https://doi.org/10.33238/ReBECEM.2020.v.4.n.3.24906

significados que se geram e reconstroem no ato de aprender (LATORRE, 2004). A sua atenção esteve particularmente centrada na interpretação dos significados das ideias e ações das crianças, manifestados nos momentos de interação com os objetos, com os seus colegas e com o próprio educador-investigador, e no modo como iam sendo (re)construídos e negociados no seio do grupo. Assim, a ação, a observação e a interpretação dos dados estão interligados e informam-se entre si, de forma interativa e recursiva, mantendo-se a interpretação contextualizada e próxima da sua fonte (GRAUE; WALSH, 2003).

Os dados gerados foram registados sob a forma de notas de campo, gravações áudio, fotografias e alguns registos de observações efetuados pelas crianças, como, por exemplo, desenhos e outros registos iconográficos. Com base nestes dados foram elaborados, logo a seguir a cada intervenção semanal, diários de atividade - narrativas descritivas e reflexivas sobre os acontecimentos mais relevantes ocorridos em contexto de sala (GRAUE; WALSH, 2003). Os diários constituíram, simultaneamente, um método de registo de dados e uma estratégia de reflexão e modelação do processo de exploração das atividades e das aprendizagens que as crianças iam gradualmente construindo (ZABALZA, 2004). Segundo Newman (2000), o ato de criar uma narrativa permite distanciarmo-nos dos nossos juízos e interpretações, influenciados por valores culturais, e oferece uma oportunidade para que o nosso trabalho seja aberto à inspeção de outros.

O processo de exploração de cada atividade, como unidade de análise representado no diário, é composto por uma sequência de momentos de aprendizagem, que correspondem a unidades de análise mais particulares. Cada uma dessas unidades de análise é portadora de um sentido específico - "unidade de significado" (RATNER, 2002), no processo de aprendizagem. Assim, no diário da atividade sobre a flutuação de objetos em água, começou-se por identificar a sequência de unidades de significado, tendo como referência as questões de investigação anteriormente definidas. Em seguida, procedeu-se à análise interpretativa do conteúdo de cada unidade identificada.

Em termos avaliativos, os dados contidos no diário não permitem, por um lado, fazer inferências quanto ao grau de aprendizagem alcançado individualmente pelas crianças. Por outro lado, não atendem à dimensão temporal e à dinâmica interna do processo de construção de significados, pois, segundo Coll e Martín (2001), “o alcance e a profundidade das aprendizagens realizadas não se manifestam, por vezes, senão depois de um certo tempo" (p. 210). Assim, dois meses após a exploração da atividade, com as férias de verão de permeio, as crianças responderam a duas questões de itens verdadeiros (V) e 
DOI:https://doi.org/10.33238/ReBECEM.2020.v.4.n.3.24906

falsos (F), com vista a avaliar, ao fim daquele período de tempo, o nível de compreensão e retenção das aprendizagens realizadas ${ }^{4}$. As crianças responderam individualmente aos itens na presença do educador-investigador, que os leu e lhes concedeu o tempo necessário para responderem. As respostas corretas foram depois organizadas em gráficos de distribuição de frequências. No entanto, a compreensão das aprendizagens realizadas requer que as crianças não incorram em incoerências entre itens. Por isso, na questão 1, identificaram-se os vários tipos de resposta e as incoerências em que incorrem, as quais foram organizadas em tabelas de frequências.

\section{Resultados}

Apresentam-se os resultados da análise do diário da atividade "flutua ou afunda na água" e da avaliação das aprendizagens realizadas pelas crianças.

\section{- As ideias iniciais das crianças}

A atividade começa com a identificação do conhecimento prévio das crianças.

- O que quer dizer "flutuar”? E “afundar”? Excerto do diário:

As crianças referem as seguintes ideias: "É ficar a boiar, assim como as pessoas na praia"; "Quem sabe nadar flutua"; "É ficar em cima na água"; "E como os barcos". "E o que quer dizer afundar?" O Gabriel responde: "é ir para o fundo da água". Outras referem: "Vão ao fundo"; "Afundam-se". As restantes concordam com esta ideia.

Através do questionamento é efetuado o levantamento das ideias prévias das crianças sobre o significado de "flutuar" e "afundar". Nas respostas, as crianças recorrem às suas vivências pessoais para significar que um objeto está a flutuar quando ele "fica" ou “está em cima da água, a boiar", e afundar quando "vai para o fundo da água".

- Que objetos flutuam e afundam na água?

Os objetos mencionados pelas crianças relacionam-se, uma vez mais, com as suas experiências do quotidiano, sendo referidos, como exemplos de corpos que flutuam na água, o ser humano, a bola, as boias, os brinquedos de plástico e os barcos. Verifica-se uma maior tendência a serem referidos exemplos de corpos flutuantes. Somente as "pedrinhas" são mencionadas como exemplos de corpos que afundam na água. Apesar do reduzido número, estes exemplos corroboram algumas tendências identificadas por outros autores

\footnotetext{
${ }^{4}$ A utilização destas questões de avaliação teve apenas uma finalidade investigativa, pois na educação préescolar a avaliação das aprendizagens assume um caráter formativo, centrado "na documentação do processo e na descrição da aprendizagem da criança” (SILVA et al., 2016, p.15).
} 
DOI:https://doi.org/10.33238/ReBECEM.2020.v.4.n.3.24906

nos exemplos de objetos flutuantes referidos por crianças da mesma faixa etária (COSTA, 2013; JOUNG, 2009).

- Por que razão alguns objetos flutuam e outros afundam?

As explicações das crianças fazem referência a uma única característica física do objeto: a) o peso: "Porque uns são pesados e outros são levezinhos"; b) o tamanho: "porque são muito pequeninos e não vão ao fundo"; c) o material de que é feito: "Porque são feitos de coisas diferentes". A quantidade de água é também assumida, por algumas, como um fator que interfere na flutuabilidade dos objetos ("Porque tem muita água no mar e segura as coisas em cima"), o que a ser verdade, um grão de areia, por exemplo, flutuaria no mar, face à imensa quantidade de água lá existente.

\section{- Investigando a flutuabilidade de diferentes objetos na água}

Vários momentos de aprendizagem, a seguir designados pelas letras A, B, C, e D, foram identificados na análise do diário da atividade.

A. As crianças exploram e identificam os objetos.

A exploração dos materiais e objetos constitui um momento de grande agitação, curiosidade e entusiasmo. Foram utilizados objetos familiares, pois estes ajudam as crianças a fazerem uso produtivo das suas experiências anteriores como recursos de aprendizagem (HSIN; WU, 2011). Durante algum tempo, as crianças interagiram com os colegas e com os objetos, na tentativa de os identificarem: "Olha, isto é uma concha da praia"; "Uma rolha do vinho"; "Ei..., um parafuso!"; "Molas de madeira para prender a roupa"; [...]. De entre os diversos objetos, apenas o "clipe" suscitou algumas dúvidas, tendo sido identificado como um "agrafo" ou um "alfinete".

B. O que irá acontecer a cada objeto se os colocarem na água?

- Preveem e registam o comportamento dos objetos na água. Excerto do diário:

As crianças elaboram previsões, registram-nas numa tabela e partilham-nas com as outras: "Eu acho que o parafuso vai ao fundo" (Rodrigo); "Eu também, mas o outro não vai, porque é de plástico" (Lara); "Eu acho que vai ficar em cima... é levezinho" (Rafael); "A noz vai flutuar" (Pedro). [...] "A bola também flutua" (Rafael). "Porque é leve e o que é levezinho vai a cima e o que é pesado vai a baixo" (Gabriel).

As explicações baseiam-se agora unicamente na característica "peso" dos objetos. Trata-se de uma

Figura 1: Registo das previsões das criancas

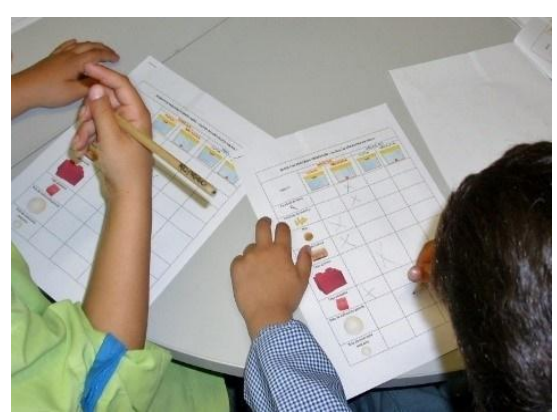

Fonte: Autoria própria 
DOI:https://doi.org/10.33238/ReBECEM.2020.v.4.n.3.24906

generalização baseada na experiência quotidiana das crianças com objetos flutuantes, que, na linguagem corrente, se dizem "leves" (objetos feitos de madeira, cortiça, plástico, etc.), e com objetos não flutuantes, que vulgarmente se dizem "pesados" (objetos de metal, pedras, etc.). Algumas esboçam essa generalização de acordo com o seguinte esquema, o qual traduz um raciocínio causal linear na explicação da flutuação e afundamento dos objetos: "leve flutua" e "pesado afunda".

- Sugerem uma forma de testar as suas previsões. Excerto do diário:

Quando questionadas sobre o que devem fazer para saberem se as suas previsões estão corretas ou não, as crianças sugerem "experimentar". Pergunto às crianças o que iremos precisar: "Precisamos desta bacia grande"; "E de água!"; "Muitas coisas para meter lá dentro para ver o que acontece"; "Estas coisas que temos aqui (os objetos) para ver se é como dissemos". "Eu quero encher, eu quero encher" - pedem várias crianças, bastante entusiasmadas.

Através das sucessivas contribuições, as crianças constroem coletivamente um plano simplificado para testarem as suas previsões. No plano estão presentes os seguintes elementos: material (“bacia grande”, “água”, “coisas”); procedimentos (“encher”, "meter lá dentro"); observação ("para ver o que acontece").

- Testam as previsões e elaboram explicações. Excerto do diário:

Todos estão impacientes para experimentar. Começam pelo parafuso. "Ei foi ao fundo" - reagem as crianças, quando o Rafael o coloca na água. "Por que é que ele foi ao fundo?" - Pergunto. "Porque é muito pequenino" (Afonso) "Porque é pesado" (Rodrigo). "E este parafuso de plástico?" "Vai acima" (várias crianças). "Por que é que ele não afundou?" "Porque é levezinho" (várias). "Agora é a noz!" "A noz flutua" - observam. "Por que será que a noz flutua?" "Porque não tem buracos e é leve". "E parece um barquinho". "A rolha de cortiça flutua." - Referem, ao verem as suas previsões confirmadas. "Por que é que acham que a rolha flutuou?" "Porque é leve" (várias). [...].
Figura 2: As crianças testam as previsões

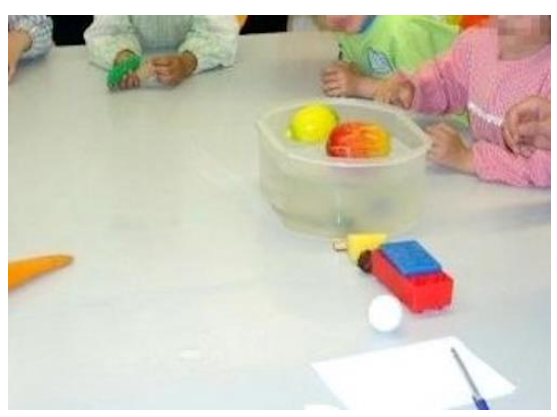

Fonte: Autoria própria

À medida que as crianças testam os objetos e quando questionadas, a maioria continua a utilizar a característica "peso" para justificar o diferente comportamento dos objetos na água.

- Refletem sobre casos particular que contrariam as suas ideias. Excerto do diário:

Sugiro que testem uma maçã natural, muito mais pesada do que qualquer um dos objetos já testados. As previsões sugerem que afunda, por ser pesada. Quando a colocam na água, o Gonçalo refere: "Isso é estranho! Ninguém acertou". "Se calhar não é só o peso que importa! O que acham?" - Pergunto. "Ela é pesada e flutua e o parafuso é leve e foi ao fundo" (Guilherme). "Se fosse só o peso, um navio afundava e uma pedrinha flutuava! Que acham?" Algumas ficam 
DOI:https://doi.org/10.33238/ReBECEM.2020.v.4.n.3.24906

pensativas. Porém, outras exteriorizam o seu pensamento, admitindo a possibilidade de os objetos pesados poderem flutuar: "Um navio grande pesa muito e flutua mesmo" (Rafael); "A maçã também é pesada e flutuou e isto é levezinho (o parafuso) e afundou" (Afonso).

O esquema explicativo "leve flutua" e "pesado afunda" é posto agora em causa, através do confronto com a evidência de um outro objeto mais pesado que flutua na água e com a evocação de situações familiares, que contrariam essa explicação. A inquietação cognitiva gerada e a, consequente, interação social, estimulada pelo questionamento da educadora, favorecem a revisão crítica das ideias previamente enunciadas, começando algumas a admitir a existência de objetos pesados que flutuam e de leves que afundam.

C. Quando um objeto está a flutuar, quem é que o está a segurar?

- Observam, refletem e tentam generalizar. Excerto do diário:

Prontamente referem que "é a água". Solicitadas a colocarem a bola no fundo de um recipiente com água, referem: "Salta para fora" (Afonso). "Vem para cima outra vez" (Rui). "Não dá pra ficar em baixo se a largar" (Pedro). "O que é que sentem quando empurram a bola?" - Pergunto. "Força e água" (Luca). Quem é que será que está a fazer essa força? "É a água!” (Gonçalo). "E vocês estão a fazer força para a bola ir para onde?" "Para baixo" (várias). "E a força que sentem é para baixo?" "Não, é para cima a empurrar a bola" (Gonçalo). "Então o que é que nós descobrimos?" "Que a água tem muita força" (várias). "E tem força para por coisas a flutuar." (Luca). "Será também por isso que um barco muito grande flutua?" "Sim, porque algumas coisas também têm força pra baixo, mas a água tem mais porque é muito forte" (Inês). "A água é mais forte que o barco e ele flutua" (Pedro). "É porque a água tem força" (Manuel). "Tem mais força que algumas coisas e segura-as em cima” (Gabriel).

As crianças facilmente compreendem que a água exerce força sobre a bola, empurrando-a na vertical e para cima - impulsão. Para além de sentirem essa força, o seu efeito na subida da bola, quando largada do fundo do recipiente com água, é muito percetível e entusiasmante para as crianças. Através da reflexão promovida pelas questões do educador, algumas são capazes de esboçar uma primeira tentativa de relacionarem a força da água e o peso do objeto, para explicarem a situação do objeto a flutuar: "algumas coisas também têm força pra baixo, mas a água tem mais, porque é muito forte"; "Tem mais força que algumas coisas e segura-as em cima”.

- Refletem sobre a ideia de a água exercer força em todos os objetos nela colocados.

"Será que a água empurra para cima todos os objetos ou só os que flutuam?" - Pergunto. "Só os que flutuam" (várias). "Pensem no parafuso que ficou no fundo. Será que água também faz 


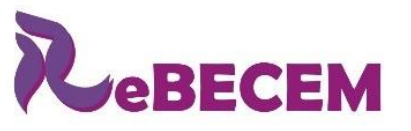

DOI:https://doi.org/10.33238/ReBECEM.2020.v.4.n.3.24906

força sobre ele?" "Não, porque ficou em baixo" (várias). "E se a água não tiver força que chegue para por o parafuso a flutuar?" Esta questão suscita reflexão e o surgimento de opiniões divergentes: a água só exerce força nos objetos flutuantes e a água exercer força em todos os objetos nela introduzidos. Contudo, esta última é defendida apenas por duas crianças.

Esta é uma ideia intuitiva vulgarmente referida pelas crianças, quando sujeitas a este tipo de reflexão: a água só exerce uma ação sobre o objeto no caso da flutuação (SÁ, 2002). A força exercida pela água ocorre analogamente nos objetos que não flutuam. Porém, a ideia de que a ação da água se exerce sobre todos os objetos nela introduzidos é uma generalização que poderá não estar ao alcance de crianças destas idades.

D. Classificam, registam e comparam as observações com as previsões iniciais.

Com base nas suas observações, as crianças formam dois conjuntos de objetos, os que flutuaram e os que afundaram. Efetuam contagens dos elementos de cada conjunto e estabelecem relações de grandeza entre eles (maior/menor). A atividade termina com o registo das observações efetuadas, de modo a que as crianças tomem consciência das suas previsões iniciais, daquelas que foram confirmadas e das que foram refutadas. Os registos escritos das suas ideias e dos dados da evidência promovem essa tomada de consciência.

Figura 4: Excerto ilustrativo da ficha de registo das previsões e observações

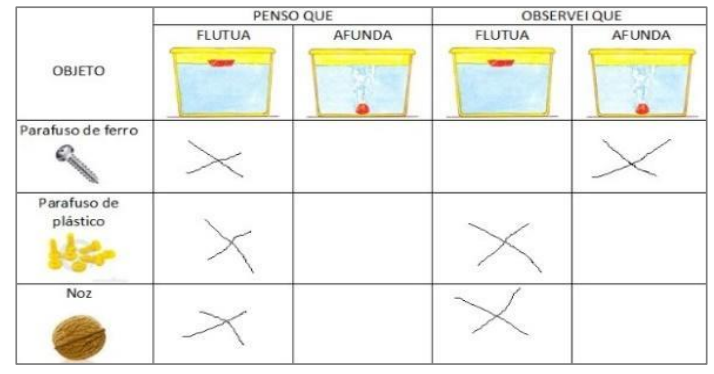

Fonte: Autoria própria

\section{- Avaliação das aprendizagens individuais das crianças}

Dois meses após a exploração da atividade, as crianças responderam individualmente às seguintes questões de avaliação:

Quadro 1: Questão de avaliação 1

1. Ouve as frases que te vou ler e assinala com um $\mathrm{V}$ as que consideras verdadeiras e com um $\mathrm{F}$ as que consideras falsas.

a) Os objetos leves flutuam e os pesados vão ao fundo.

b) Todos os objetos pesados vão ao fundo.

c) Há objetos pesados que flutuam e objetos leves que vão ao fundo.

Fonte: Autoria própria 
DOI:https://doi.org/10.33238/ReBECEM.2020.v.4.n.3.24906

Quadro 2: Questão de avaliação 2

2. Observa a figura. Ouve as frases que te vou ler e assinala com um $\mathrm{V}$ as que consideras verdadeiras e com um $\mathrm{F}$ as que consideras falsas.

a) A bola está a flutuar.

b) A água empurra a bola para cima.

c) A pedra não sobe porque a água não tem força que chegue.

d) A água empurra só os objetos que flutuam como a bola.

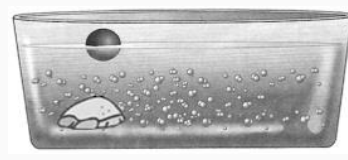

Fonte: Autoria própria

Em gráficos de barras apresenta-se o número e percentagem de respostas corretas assinaladas em cada item das questões anteriores.

Gráfico 1: Respostas corretas à questão

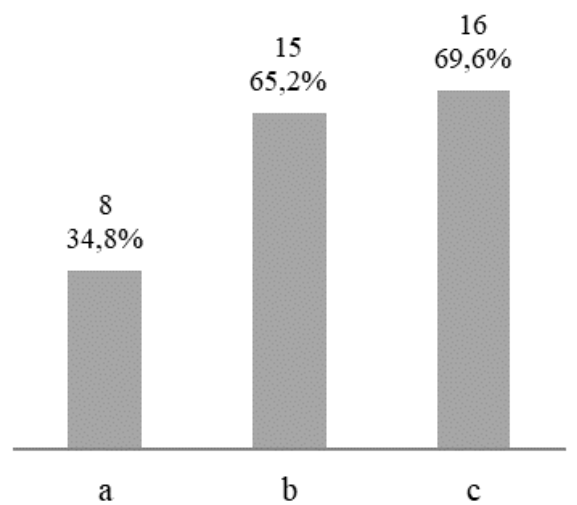

Fonte: Autoria própria

Gráfico 2: Respostas corretas à questão 2

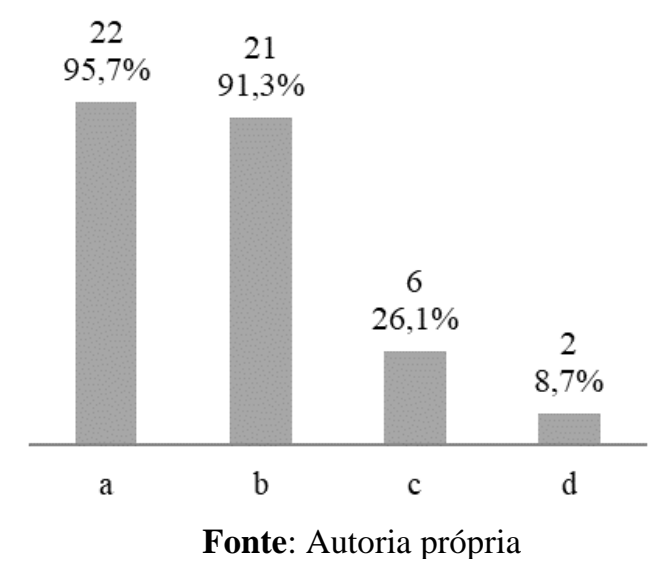

Na questão de avaliação 1, os resultados do item a) evidenciam que o esquema explicativo "leve flutua" e "pesado afunda" continua ainda a ser sustentado pela maioria das crianças. Trata-se, pois, de uma construção intuitiva fortemente impregnada nas suas mentes, que está associada a fatores de natureza percetiva e experiencial (HSIN; WU, 2011; LONGHINI et al., 2011).

Apenas 34,8\% das crianças o consideram incorreto. No entanto, esta percentagem de respostas, comparada com a obtida nos itens b) e c), sugere a existência de incoerências nas mentes das crianças. Procedeu-se, assim, à análise das respostas item a item de cada criança, que permitiu identificar, conforme a tabela seguinte, diferentes tipos de resposta e suas respetivas frequências. 
DOI:https://doi.org/10.33238/ReBECEM.2020.v.4.n.3.24906

Tabela 1: Tipos de respostas à questão 1

\begin{tabular}{|c|c|c|c|c|}
\hline & \multirow{2}{*}{\multicolumn{2}{|c|}{ Tipos de resposta }} & \multicolumn{2}{|c|}{ Frequência $(\mathrm{N}=23)$} \\
\hline & & & $n$ & $\%$ \\
\hline$\overline{\text { a) }}$ & Todos os itens corretos & & 6 & 26,1 \\
\hline b) & Todos os itens incorret & & 4 & 17,4 \\
\hline \multirow{2}{*}{\multicolumn{2}{|c|}{ c) 1 ou 2 itens incorretos }} & Item a) verdadeiro (inc.) & 11 & 47,8 \\
\hline & & Item a) falso (cor.) & 2 & 8,7 \\
\hline \multicolumn{3}{|c|}{ Total } & 23 & 100 \\
\hline
\end{tabular}

Apenas 6 crianças $(26,1 \%)$ evidenciam coerência interna nas respostas aos três itens: consideram incorreto aquele esquema explicativo e manifestam, simultaneamente, o conhecimento de que "nem todos os objetos pesados afundam" e, portanto, "existem objetos pesados que flutuam e objetos levem que afundam". Atendendo a que, durante a exploração da atividade, a ideia "leve flutua" e "pesado afunda" era consensual entre as crianças, pois na altura nenhuma se opôs ou manifestou uma explicação divergente, este resultado sugere uma evolução assinalável na aprendizagem destas crianças.

Porém, a maioria erra um ou dois itens $(56,5 \%)$ e aquelas que consideram o item a), "Os objetos leves flutuam e os pesados vão ao fundo", verdadeiro $(11 ; 47,8 \%)$ incorrem em incoerências que giram em torno dos contrastes entre os itens a) versus b) e a) versus c). Nas várias combinações de resposta a esses itens, foram identificadas as incoerências assinaladas na tabela seguinte.

Tabela 2: Combinações entre o item a), "Os objetos leves flutuam e os pesados vão ao fundo" e o item b) e c)

\begin{tabular}{|c|c|c|c|}
\hline \multirow{2}{*}{ Contraste } & \multirow{2}{*}{ Combinações identificadas } & \multicolumn{2}{|c|}{ Frequência $(\mathrm{N}=11)$} \\
\hline & & $n$ & $\%$ \\
\hline \multirow{2}{*}{ a) $v s$ b) } & Sim, e todos os pesados vão ao fundo. & 2 & 18,2 \\
\hline & Sim, e nem todos os pesados vão ao fundo.* & 9 & 81,8 \\
\hline \multirow{2}{*}{ a) $v s \mathrm{c})$} & $\begin{array}{l}\text { Sim, e há objetos pesados que flutuam e objetos leves } \\
\text { que vão ao fundo.* }\end{array}$ & 8 & 72,7 \\
\hline & $\begin{array}{l}\text { Sim, e não há objetos pesados que flutuam e objetos } \\
\text { leves que vão ao fundo. }\end{array}$ & 3 & 27,3 \\
\hline
\end{tabular}

Depreende-se, desta forma, que a maioria deste subgrupo de 11 crianças evidencia um conhecimento fragmentado, em que o novo coexiste com o esquema intuitivo "leve flutua" e "pesado afunda". Apesar de alguns autores desvalorizarem as mudanças que envolvam adição de conhecimento, Havu-Nuutinen reconhece que, no caso de crianças pequenas, "a adição de conhecimento é o ponto de partida para o processo de mudança 
DOI:https://doi.org/10.33238/ReBECEM.2020.v.4.n.3.24906

conceitual" (2005, p. 260). Nesta perspetiva, de acordo com Vosniadou et al. (2008), o novo conhecimento é adicionado ao quadro explicativo inicial da criança, destruindo a sua coerência interna até que o mesmo seja reestruturado, de modo a tornar-se mais consistente com as teorias científicas atualmente aceites. Este processo requer que as crianças tenham consciência das suas próprias crenças e teorias explicativas, de modo a reconhecerem as contradições e incoerências em que incorrem, e uma aprendizagem intencional (VOSNIADOU, 2010).

Em relação aos resultados da questão de avaliação 2, verifica-se que as crianças não apresentam dificuldades em reconhecer um objeto a flutuar à superfície da água e que, nessas circunstâncias, a água exerce sobre ele uma força na vertical e de sentido para cima. Porém, sugerem também a dificuldade de estabelecerem qualquer relação causal entre a ação da água e o peso do objeto para explicarem o seu afundamento, pois permanece a ideia intuitiva de que a força exercida pela água somente ocorre nos objetos que flutuam.

\section{Considerações finais}

Este estudo pretendeu promover, num contexto de educação pré-escolar, uma abordagem prática e investigativa na iniciação ao fenómeno da flutuação de objetos em água. As questões de investigação inicialmente definidas implicaram identificar as conceções prévias das crianças sobre a flutuação, averiguar as aprendizagens por elas realizadas e descrever alguns processos promotores dessas aprendizagens.

A elicitação das conceções prévias das crianças sobre a flutuação de objetos em água ocorreu no contexto da exploração de uma atividade projetada para se promover, a partir desse conhecimento, um melhor entendimento da flutuação. Assim, não foi objetivo deste estudo identificar exaustivamente as conceções das crianças, pois os dados obtidos reportam-se apenas às respostas de uma pequena amostra ao questionamento do educadorinvestigador.

Em relação ao significado da palavra flutuar e afundar, as crianças consideram que um corpo flutua quando ele fica em cima da água, "a boiar como as pessoas ou os barcos", e afunda quando "vai para o fundo". Segundo Joung (2009), esta é a principal posição referida pelas crianças, em relação aos objetos flutuantes. Porém, um corpo pode também flutuar totalmente submerso, mas livremente suspenso, como, por exemplo, os peixes ou os submarinos. Nenhuma criança contemplou esta possibilidade ou foi sobre ela questionada. Biddulph e Osborne (1984) verificaram que, nesta situação, algumas crianças 
mais velhas não consideram que o corpo esteja a flutuar, assim como a parte submersa de um corpo que se encontre a flutuar à superfície da água.

Em concordância com outros autores (BIDDULPH, OSBORNE, 1984; HSIN, WU, 2011; JOUNG, 2009; LONGHINI et al., 2011; KALLERY, 2015), este estudo sugere que as primeiras tentativas de explicação das crianças, para o fenómeno da flutuação, incluem uma única característica física dos objetos, como o tamanho, o peso e o material de que são feitos. Estas explicações estão normalmente enraizadas em experiências percetivas (BUTTS et al.,1993; HSIN; WU, 2011). Neste estudo, a quantidade de água foi também assumida, por algumas crianças, como um fator que interfere na flutuabilidade dos corpos, o que, a ser verdade, um grão de areia, por exemplo, flutuaria no mar, face à imensa quantidade de água lá existente.

Contudo, o "peso" parece ser a característica mais utilizada pelas crianças destas idades para explicarem a flutuação e afundamento dos objetos. Este dado está em linha com o estudo de Hsin e Wu (2011), que mostrou também que as crianças de 4 e 5 anos viram o peso como o fator dominante e que a maioria considerou que um objeto afunda porque é pesado. Esta é uma ideia intuitiva baseada não só na perceção, mas também em experiências do quotidiano, nas quais objetos que, na linguagem corrente, se dizem pesados afundam normalmente na água (LONGHINI et al., 2011). Trata-se de um primeiro esforço de generalização, baseado num raciocínio causal linear, segundo a qual "os objetos pesados afundam e os leves flutuam".

No desenvolvimento de teorias explicativas mais concordantes com a realidade foi possível verificar que o confronto do esquema explicativo "leve flutua" e "pesado afunda" com a evidência ou com a evocação de situações familiares que o contrariam gera nas crianças uma inquietação cognitiva. A consequente interação social que se estabelece, por via do questionamento do educador-investigador, incrementa o nível de reflexão e favorece a revisão crítica das ideias previamente enunciadas (HSIN; WU, 2011; SÁ, 2002). Algumas crianças tomam consciência das limitações e contradições das suas explicações, começando a admitir a existência de objetos pesados que também flutuam (ex.: "Um navio grande pesa muito e flutua") e de leves que afundam (ex.: "A maçã também é pesada e flutuou e isto é levezinho (o parafuso) e afundou”). Segundo Vosniadou (2010), este tipo de consciência constitui uma condição essencial para que ocorram mudanças nas suas próprias teorias específicas sobre o mundo físico e, consequentemente, fornece uma chave para incentivar a mudança conceitual em crianças pequenas (HAVU-NUUTINEN, 2005). 
No entanto, dois meses após a intervenção, os resultados obtidos na primeira questão de avaliação revelam que as crianças desenvolveram aprendizagens com diferentes níveis de sistematicidade e coerência interna. Apenas seis crianças consideraram incorreto aquele esquema explicativo e revelaram, simultaneamente, o conhecimento de que "nem todos os objetos pesados afundam" e, portanto, "existem objetos pesados que flutuam e objetos levem que afundam”. A maior parte manifestou um conhecimento fragmentado, em que o novo conhecimento coexiste com o esquema intuitivo "leve flutua" e "pesado afunda", o que revela tratar-se de um esquema intuitivo muito impregnado nas suas mentes.

A tentativa de colocarem uma pequena bola no fundo da água de um recipiente revelou-se também eficaz na promoção da compreensão de que a água exerce força sobre a bola, empurrando-a na vertical e para cima. Porém, a combinação dos dados do diário com os resultados da segunda questão de avaliação revela a dificuldade de reconhecerem que essa força se exerce igualmente sobre os objetos que afundam. Esta dificuldade impede que as crianças estabeleçam qualquer relação causal entre a ação da água e o peso do objeto para explicarem o seu afundamento. A ideia de que a ação da água se exerce sobre todo e qualquer objeto nela introduzida é uma generalização que poderá não estar ao alcance de crianças destas idades. Falta-lhes o efeito observável da força, ou seja, o subir e ficar a flutuar (SÁ, 2009). No entanto, mediante a reflexão induzida pelo questionamento do educador, algumas são capazes de esboçar uma primeira tentativa de relação causal entre as duas forças, a força da água e o peso do objeto, em situação de flutuação (ex.: "algumas coisas também têm força pra baixo, mas a água tem mais, porque é muito forte"; "Tem mais força que algumas coisas e segura-as em cima").

O papel ativo e reflexivo das crianças, estimulado e guiado pela ação do adulto, é fundamental no processo de aprendizagem. No caso analisado, as crianças: a) começam por comunicar os significados pessoais que atribuem às palavras "flutuar" e "afundar"; b) referem exemplos de objetos que flutuam e afundam na água; c) refletem sobre as suas ideias, que enfatizam as características físicas dos objetos para justificar o seu comportamento na água; d) identificam os materiais a utilizar na atividade; e) preveem e registam o comportamento dos objetos na água; f) sugerem uma forma de testar as suas previsões; g) testam as previsões elaboradas; h) refletem sobre a inconsistência das suas ideias, quando confrontadas com situações conflituantes que contrariam as suas próprias teorias explicativas; i) sentem e observam o efeito da força da água, quando tentam colocar uma bola no fundo da água; j) refletem sobre a ideia de a ação da água se exercer sobre 
DOI:https://doi.org/10.33238/ReBECEM.2020.v.4.n.3.24906

todos os objetos nela colocados; 1) efetuam as correspondentes observações e classificam os objetos, de acordo com o critério flutua/afunda; m) procedem ao registo individual das aprendizagens realizadas.

Reforçamos, assim, a convicção de que as crianças destas idades são capazes de assumir uma atitude ativa e investigativa na procura do saber, executando, com a ajuda e a orientação do adulto, um conjunto de processos científicos simples (FRENCH; WOODING, 2013; GERDE et al., 2013), mesmo antes de lhes ser formalmente ensinada a linguagem e as práticas da ciência (TEO et al., 2017).

Tudo isto implica, naturalmente, um grande envolvimento intelectual e socioafetivo da criança, mas é indissociável de uma intervenção planificada e intencionalmente orientada por parte do educador. O seu apoio e orientação são fundamentais para as crianças melhorarem as suas ideias iniciais sobre a flutuação. Através do questionamento, como estratégia de scaffolding, o educador vai sustentando, orientando e regulando a atividade cognitiva das crianças (CHIN, 2006; HSIN; WU, 2011), ajudando-as a escalarem progressivamente níveis mais elevados de aprendizagem e cognição. Os resultados deste estudo permitem sustentar, em consonância com outros autores (BUTTS et al., 1993; HAVU-NUUTINEN, 2005; HSIN; WU, 2011), que as atividades de aprendizagem sobre a flutuação e o afundamento devem ir além das experiências manipulativas das crianças com os objetos.

Por último, diríamos ainda que a análise apresentada neste artigo sobre o processo de exploração da atividade pode constituir uma ferramenta formativa de apoio aos educadores para, em contextos similares, evocarem e promoverem idêntico processo de exploração com as suas crianças.

\section{Referências}

BIDDULPH, F.; OSBORNE, R. Pupil's ideas about floating and sinking. Research in Science Education, Dordrecht, v. 14, p. 114-124, Dec. 1984. DOI: https://doi.org/10.1007/BF02356797

BUTTS, D.P.; HOFMAN, H.M.; ANDERSON, M. Is hands-on experience enough? A study of young children's view of sinking and floating objects. Journal of Elementary Science Education, Macomb, Illinois, v. 5, n.1, p. 50-64, Jan.1993. DOI: https://doi.org/10.1007/BF03170644 
DOI:https://doi.org/10.33238/ReBECEM.2020.v.4.n.3.24906

CHIN, C. Classroom Interaction in Science: Teacher questioning and feedback to students' responses. International Journal of Science Education, Abingdon, v. 28, n. 1, p. 1315-1346, Fev. 2006. DOI: 10.1080/09500690600621100

COLL, C.; MARTÍN, E. A avaliação da aprendizagem no currículo escolar: uma perspectiva construtivista. In: C. Coll et al (Eds). O construtivismo na sala de aula. Novas perspectivas para a acção pedagógica. Porto: Edições ASA, 2001, p.196-221.

COSTA, L. Realizar experiências com a água: uma abordagem experimental das ciências no $1^{\circ}$ ano de escolaridade. Dissertação (Mestrado em Educação Pré-escolar e Ensino do $1^{\circ}$ Ciclo do Ensino Básico) - Instituto de Educação, Universidade do Minho, Braga, p. 73. 2013. Disponível em: http://repositorium.sdum.uminho.pt/handle/1822/28709

ESHACH, H.; FRIED, M. Should science be taught in early childhood? Journal of Science Education and Technology, Dordrecht, v. 14, n. 3, p. 315-336, Sept. 2005. DOI: https://doi.org/10.1007/s10956-005-7198-9

FIOLHAIS, C. De pequenino é que se torce o destino: ciência no jardim-de-infância. Cadernos de Educação de Infância, Lisboa, v. 95, p. 49-54, jan/abr. 2012.

FRENCH, L. Science as the center of a coherent, integrated early childhood curriculum. Early Childhood Research Quarterly, Duxford, Cambridge, v. 19, n. 1, p. 138-149, Jan./Abr. 2004. DOI: https://doi.org/10.1016/j.ecresq.2004.01.004

FRENCH, L.; WOODING, S. Science education in the early years. In: SARACHO, O.; SPODEK, B. (Eds.), Handbook of research on the education of young children. New York: Routledge, 2013, p. 179-196.

FURMAN, M. O ensino de Ciências no Ensino Fundamental: colocando as pedras fundacionais do pensamento científico. São Paulo: Sangari Brasil, p. 20. 2009. Disponível em: http://dominiopublico.mec.gov.br/download/texto/is000002.pdf

GERDE, H.; SCHACHTER, R.; WASIK, B. Using the Scientific Method to Guide Learning: An Integrated Approach to Early Childhood Curriculum. Early Childhood Education Journal, Dordrecht, v. 41, n. 5, p. 315-323. Feb. 2013. DOI: https://doi.org/10.1007/s10643-013-0579-4

GRAUE, M. E.; WALSH, D. J. Investigação Etnográfica com Crianças: Teorias, métodos e ética. Lisboa: Fundação Calouste Gulbenkian, p. 313. 2003.

GUBA, E. G.; LINCOLN, Y. S. Competing Paradigms in Qualitative Research. In: N. DENZIN, N.; LINCOLN, Y. (Eds.), Handbook of qualitative research. Thousand Oaks, CA: Sage, 2000, p. 105-117. 
DOI:https://doi.org/10.33238/ReBECEM.2020.v.4.n.3.24906

HARLEN, W. Helping children's development of inquiry skills. Inquiry in primary science education, Valeta, v. 1, p. 5-19, 2014.

HARLEN, W. Science as a key component of the primary curriculum: a rationale with policy implications. Perspectives on education Primary Science, 1, p. 4-18. London: Wellcome Trust. 2008.

HARLEN, W.; QUALTER, A. The teaching of science in primary schools (7th Edition). Abingdon: Routledge, p. 400. 2018.

HAVU-NUUTINEN, S. Examining young children's conceptual change process in floating and sinking from a social constructivist perspective, International Journal of Science Education, Abingdon, v. 27, n. 3, p. 259-279, Jun. 2005. DOI: 10.1080/0950069042000243736

HSIN, C.; WU, H. Using Scaffolding Strategies to Promote Young Children's Scientific Understandings of Floating and Sinking. Journal of Science Education and Technology, Dordrecht, 20, p. 656-666, May. 2011. DOI: https://doi.org/10.1007/s10956-011-9310-7

JONES, I.; LAKE, V. E.; LIN, M. Early Childhood Science Process Skills: Social and Developmental Considerations. In: SARACHO, O. N.; SPODEK, B. (Eds.). Contemporary perspectives on Science and Technology in Early Childhood Education. Charlotte, NC: Information Age Publishing, 2008. p. 17-40.

JOUNG, Y. Children's Typically-Perceived-Situations of Floating and Sinking. International Journal of Science Education, Abingdon, v. 31, n. 1, p. 101-127. Jan. 2009. DOI: $10.1080 / 09500690701744603$

KALLERY, M. Science in early years education: introducing floating and sinking as a property of matter, International Journal of Early Years Education, London, v. 23, n. 1, p. 31-53, Feb. 2015. DOI: 10.1080/09669760.2014.999646

KOHN, A. Preschoolers' Reasoning about Density: Will It Float? Child Development, Hoboken, New Jersey, v. 64, n. 6, p. 1637-1650, Dec.1993. DOI:10.2307/1131460

LATORRE, A. La investigación-acción. Conocer y cambiar la práctica educativa. Barcelona: Editorial Graó, p. 138. 2004.

LONGHINI, M.; NUNES, B.; GRILLO, G. Flutuação dos corpos: elementos para a discussão sobre sua aprendizagem em alunos dos anos iniciais do Ensino Fundamental. Revista Brasileira de Ensino de Física, São Paulo, v. 33, n. 3, p. 3401-3408, jul./set. 2011. DOI:

https://doi.org/10.1590/S1806-11172011000300016

MACNAUGHTON, G.; HUGHES, P. Doing action research in early childhood studies: a by step guide. Maidenhead: Open University Press, p. 264. 2011. 
DOI:https://doi.org/10.33238/ReBECEM.2020.v.4.n.3.24906

MARTINS, I.; VEIGA, M; TEIXEIRA, F.; TENREIRO-VIEIRA, C.; VIEIRA, R.; RODRIGUES, A.; COUCEIRO, F.; PEREIRA, S. Despertar para a ciência - actividades dos 3 aos 6. Lisboa: Ministério da Educação, p. 108. 2009.

NEWMAN, J. M. Action research: A brief overview. Forum: Qualitative Social Research, Berlin, v. 1, n. 1, Art. 17, Jan. 2000. DOI: http://dx.doi.org/10.17169/fqs-1.1.1127

PATRICK, H.; MANTZICOPOULOS, P. Young Children`s Motivation for Learning Science. In: TRUNDLE, K.; SAÇKES, M. (Eds.), Research in Early Childhood Science Education. New York: Springer, 2015. p. 35-66.

PATRICK, H.; MANTZICOPOULOS, P.; SAMARAPUNGAVAN, A. Integrating science inquiry with reading and writing in Kindergarten. In: SHILLADY, A. (Ed.) Exploring Science. National Association for the Education of Young Children. Washington, DC, 2013. p. 48-54.

PIAGET J. The children's conception of physical causality. Transaction, London, p. 322. 2001.

PRISCINET. Primary Science Network. This project has received funding from the European Union's Seventh Framework Programme, 2014. Disponível em: http://prisci.net/. Acesso em: 8. Jan. 2019.

RATNER, C. Subjectivity and Objectivity in Qualitative Methodology. Forum: Qualitative Social Research, Berlin, v. 3, n. 3, Art. 16, Sept. 2002. DOI: http://dx.doi.org/10.17169/fqs3.3.829

SÁ, J. Em cada criança um génio da ciência! (Web log post), 2009, Jun., 12. Disponível em: http://geniociencia.blogspot.com/2009/06/flutuacao-afundamento-sugestoes-para-os_12.html

SÁ, J. Ciências experimentais na educação pré-escolar e 1 $^{\circ}$ ciclo do ensino básico: perspetivas de formação de professores. In: VEIGA, L. (Ed.) Formar para a Educação em Ciências na educação pré-escolar e no $1^{\circ}$ ciclo do ensino básico. Coimbra: Edições IPC, 2003. p. 45-78.

SÁ, J. Renovar as Práticas no 1. ${ }^{\circ}$ Ciclo Pela Via das Ciências da Natureza. Porto: Porto Editora, p. 256. 2002.

SILVA, I.; MARQUES, L.; MATA, L.; ROSA, M. Orientações Curriculares para a Educação Pré-Escolar. Direção-Geral da Educação. Lisboa: Portugal, p. 110. 2016. Disponível em: http://www.dge.mec.pt/orientacoes-curriculares-para-educacao-pre-escolar

TEO, T. W.; YAN, Y. K.; ONG, W. L. M. An investigation of Singapore preschool children's emerging concepts of floating and sinking, Pedagogies: An International Journal, Singapura, v. 12, n. 4, p. 325-339, Sept. 2017. DOI: 10.1080/1554480X.2017.1374186 
VARELA, P. Ciências Experimentais para Crianças. Uma Proposta Didática de Construção Reflexiva de Significados e Promoção de Competências. Saarbrücken: NEA - Novas Edições Acadêmicas, p. 359. 2014.

VOSNIADOU, S.; VAMVAKOUSSI, X.; SKOPELITI, I. The framework theory approach to the problem of conceptual change. In: VOSNIADOU, S. (Ed.) International handbook of research on conceptual change. New York, NY: Routledge, 2008. p. 205-239.

VOSNIADOU, S. (2010). Instructional considerations in the use of external representations. In: Verschaffel, L. et al. (Eds.) Use of representations in reasoning and problem solving. New York, NY: Routledge, 2010. p. 36-54.

ZABALZA, M. A. Diarios de clase: un instrumento de investigación y desarrollo profesional. Madrid: Narcea, p. 168. 2004.

Recebido em: 12 de maio de 2020

Aceito em: 6 de agosto de 2020 